\title{
Recent Researches on Typhoons in Japan
}

\author{
by \\ H. Hatakeyama \\ Meteorological Research Institute \\ (Received September 16, 1954)
}

\begin{abstract}
Inhabitants in Japan suffer from strong winds and heavy rainfalls in the typhoon almost every year. Investigations on typhoons and depressions have been sedulously made by the investigators in the Central Meteorological Observatory and in the geophysical institutes of universities.

In recent years, the development in the observational techniques with Radiosonde and Rawin has made it possible to obtain reliable observational materials in an area of typhoon and even close to or even in the eye of a typhoon. In the typhoon season of 1951, the Central Meteorological Observatory of Japan started the Typhoon Research Project which included the aerological and extraordinary surface observations.

In this synthetic paper the author intends to report on the recent researches on typhoons in Japan.
\end{abstract}

\section{Researches on the structure of typhoon}

1) Aerological investigation.

Some valuable observational data on the typhoon were obtained in the swarm ascents of radio-sonde in typhoon "Kitty" at Tokyo and Tateno when it passed by Tokyo area on August 31, 1949, and on the basis of these data a number of studies were made. H. YAmAda and S. Matsuhashi[1] constructed time-crosssection on pressure and temperature anomaly at Tokyo, and compared them with those from the observations of hurricane at Tampa by R.H. Simpson [2]. They also investigated the wind distribution at the earth's surface, 10,000 and 30,000 ft altitudes by means of the composite map, and pointed out that the wind system was cyclonic within $300 \mathrm{~km}$ in distance and $30,000 \mathrm{ft}$ in altitude from the center of typhoon but there were outflows from the centre in the north-eastern quadrant at altitudes of more than 10,000 ft and distances over $300 \mathrm{~km}$. Y. MAsuda [3], who has proposed a method of calculating vertical velocity, presumed the vertical structure of typhoon calculating the vertical velocity on typhoon "Kitty" by his own method. He concluded that there exist severe downdrafts everywhere over the height of $2 \mathrm{~km}$ around the center and severe updraft regions surrounding them, and that the latter are to be considered to form the huge cloud wall surrounding the eye. He also pointed out that a typhoon moves toward the region of severe updraft, constructing composite maps for vertical velocities at 3.5 and $8 \mathrm{~km}$ levels. H. Arakawa [4] also pointed out the existence of severe down. and up-drafts at the eye and stormy area drawing, respectively, time-cross-sections on temperature and potential temperture at Tokyo during the passage of typhoon "Kitty". He also found that the 


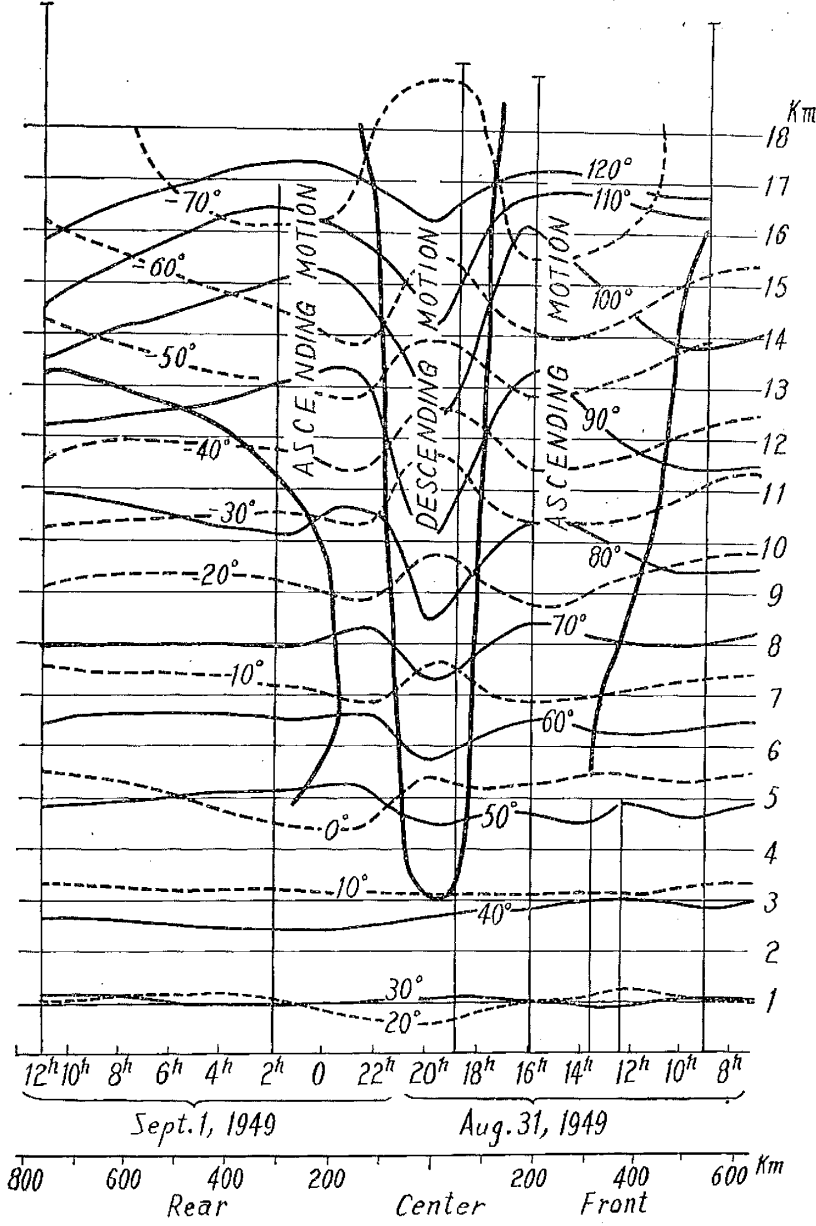

Fig. 1. Time-cross-section through the typhoon "Kitty." tropopause of typhoon "Kitty" had a multiple property, making an analysis on the tropopause, and concluded that a typhoon is accompanied by a tropopause funnel above its center and a tropopause ridge above its stormy area (Fig. 1).

M. Hashimoto and J. SAMPEI [5] pointed out that there exists a warm area which moves with the typhoon in front of it, through their analyses on pressure, temperature and tropopaise for typhoon "Kitty" by making south-north and east-west space-cross-sections through the center in addition to time-cross-sections.

Typhoons "Jane" and "Kezia". landed on the Japan islands successively in September, 1950. They caused great damages, but on the other hand they provided rather many observational data, with which many Moving Direction
Fig. 2. The horizontal distribution of relatively high and low pressure areas in "Jane" at 300 $\mathrm{mb}$. In this figure, dotted concentric circles represent distances from the surface center $2^{\circ}, 4^{\circ}, 6^{\circ}, 8^{\circ}$ and $10^{\circ}$ in latitude, and shaded areas relatively low pressure areas.

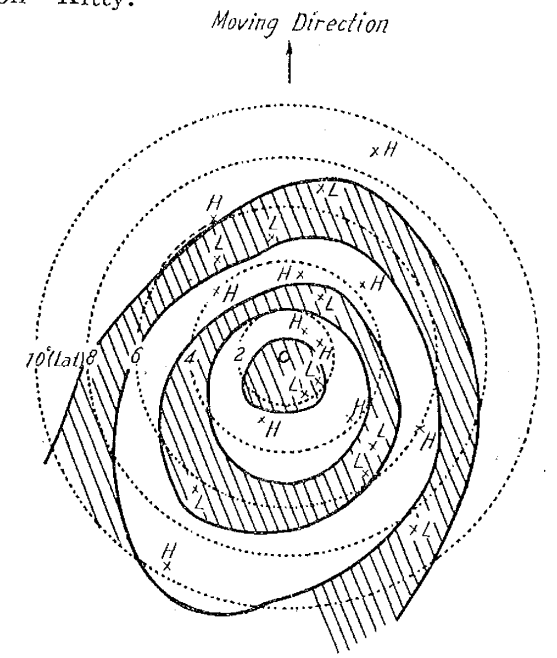


studies were made on the typhoons. Y. Masuda and M. TAkeuchi [6] made threedimensional analyses for typhoons "Jane" and "Kezia", and suggested a schematic model of the typhoon. In Fig. 2, relatively high and low pressure areas are shown on a composite map. It is clarified from the figure that, in the upper layers, relatively high and low pressure areas show a ring-shaped distribution superposing on the basic pressure field which decreases uniformly toward the center, and that the temperature field corresponds to the pressure-field. The tropopause shape is similar to that in the case of an extratropical cyclone, but the relation between the tropopause height and its temperature is contrary to the cases at middle latitudes, i.e., the tropopauses low and cold or high and warm are seen. The area of the cyclonic rotation of typhoon decreases with the height, the wind at the level where the cyclonic rotation disappears is a steering current, and the air maintaining the convective system of typhoon is that converging in the thin layer below $2 \mathrm{~km}$ height. Fig. 3 shows a schematic model of a typhoon on the basis of

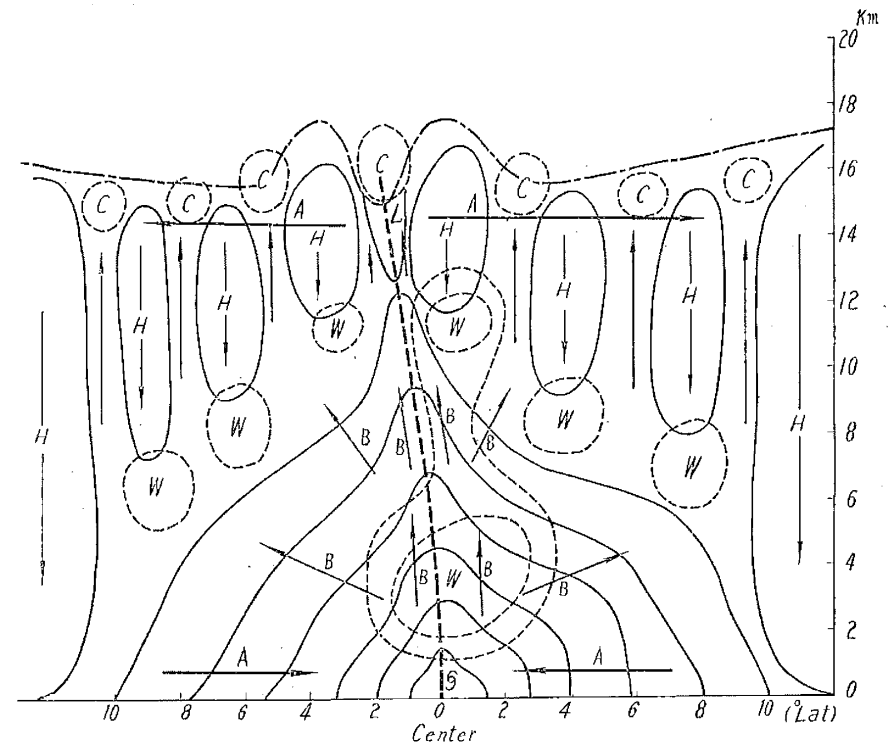

Fig. 3. Schematic model of the structure of typhoon in its mature stage.

these results. It is presumed from these results that a typhoon is not a simple convective system but has a few secondary dynamical convective systems, superposing on a basic convective system.

H. KАто[7] made analyses on typhoons "Della" (landing on Kyushu on June 20, 1949), "Kitty", "Jane" and "Kezia", from which he concluded that the height of the typhoon reaches $16 \sim 20 \mathrm{~km}$. He also made an energetic study, from which he concluded that the warm air flowing inward plays an important rôle in the maintenance of a typhoon system, and that the direction of movement of a typhoon deviates $30^{\circ}$ leftward from the direction along a steering current in the upper layer. Besides, S. Kobayashi[8] made aerological analyses for "Jane" and $\mathrm{K}$. UWAI [9] [10] for "Jane" and "Kezia". K. UwAI[11] made another series of researches on tropopause wave through aerological studies of the formation, development, movement and decay of the typhoon. 
Numbers of small disturbances, which had much influence on the weather situation near Japan, appeared in the North-western Pacific in August, 1950. S. KubotA [12] demonstrated that those tropical low pressure areas had axes leaning eastward and were of the cold core type, from his investigations on their basic state by calculating the mean values of the height of standard pressure level, temperature, wind, etc. H. ARAKAwa [13] named the small disturbances formed successively in these low-pressure area as "subtropical cyclone," and demonstrated that those which developed into midget typhoons or Mame-Taifu have the characteristics of an ordinary typhoon for the temperature and wind fields, through his investigations. on their formation and structure.

A. KASAHARA [14] made analyses on pressure and temperature fields for typhoon "Ruth" (landing on Kyushu on October 14, 1951), and concluded that a typhoon may be considered to originate and develop in the atmosphere in latent instability, and that though the isentropic surface around the center of typhoon. swells downward, this region is not one of downdraft but of updraft and that it is incorrect to consider that the origination of the high temperature area around the center is caused by the simple adiabatic compression accompanying the downdraft.

Besides, studies on the basis of the enormous observational data on typhoon. "Ruth", which were published in the Memoirs of the Central Meteorological Observatory, Vol. 37, Nos. 1 and 2 (1952) as one of the fruits of the Typhoon Research Project, are now being carried on systematically. It must be noted that important conclusions are being deduced on the essential subjects such as the structure of the typhoon, interaction of the typhoon and polar front (by H. ARAKAWA [15] and others) and so on.

2) Surface analysis.

A series of detailed studies on typhoon "Della", extending from its formation to dissipation, from which an interesting result was deduced on the dip on the pressure distribution at the earth's surface, were made by T. FujITA[16]. A. Kasahara [17] who made analyses on the amount of rain-fall and filling-up for typhoon "Kitty", found good coincidence of values computed theoretically and experimentally and concluded that the horizontal mass convergence plays an important rôle in the distribution of the amount of rainfall and filling-up of a typhoon. T. Ando [18] also analysed the rain area for typhoon "Kitty", and concluded that there are two patterns of rainfall, one due to the wave-like disturbances and another vortical, in the rain belt of a typhoon. Another series of studies on the

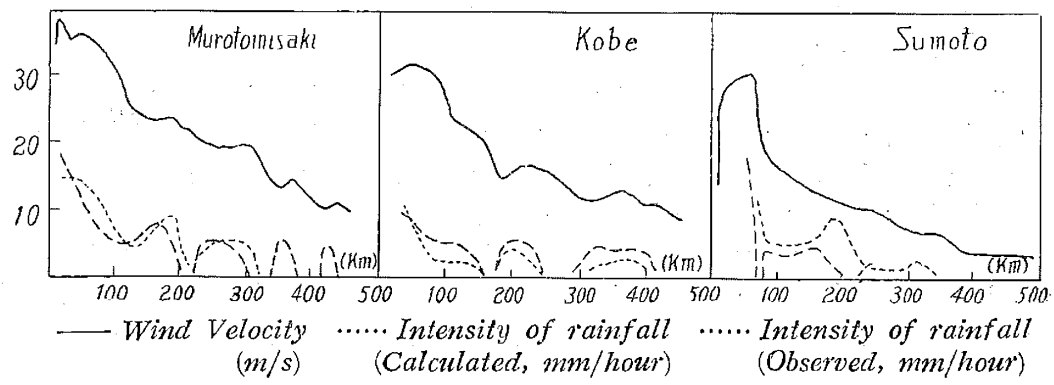

Fig. 4. Distributions of wind velocity, calculated and observed intensity of rainfall in the case of typhoon "Jane". 


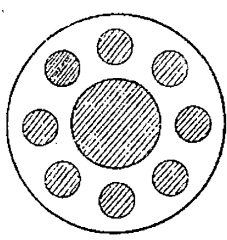

(a)

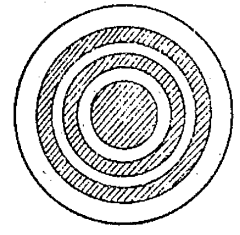

(b)

Fig. 5. Schematic vorticity distribution; (a) cellular type (b) annular type (hatched region indicate the areas of positive vorticity).

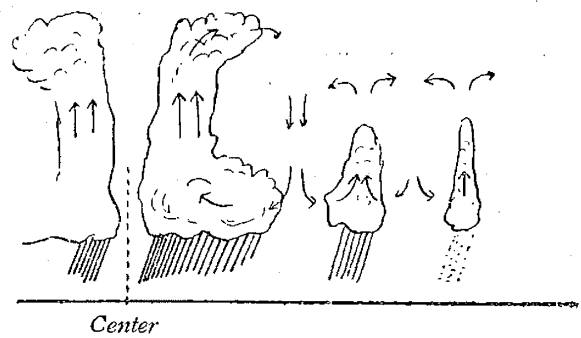

Fig. 6. Schematic cross section in a typhoon.

rain belt of a typhoon was made by K. Uwar[19]. S. SAito[20] said that there were two centers in typhoon "Jane", the primary one with an eye and the secondary without, investigating the pressure curves at various places near the track of the typhoon. K. HASHIMOTO[21] also investigated the inner region, especially the eye, for typhoon "Kezia" through the similar step. S. Syono, Y. Ogura, K. Gambo and A. Kasamara [22] made analyses on wind velocity distribution, distributions of horizontal divergence and convergence, rainfall intensity, and changes of pressure distribution with time, for typhoons "Kitty" and "Jane" so as to clarify how important a rôle the negative vorticity plays in a typhoon, and concluded that, in the microstructure of the typhoon, a small vortical cell of $50 \sim 100 \mathrm{~km}$ in radius and with positive or negative vorticity exists superposing on a typhoon. They also discussed the problems of the vibration of the vortical cell, drawing vertical cross-sections for a model typhoon on the basis of the results of their novel analyses (See Figs. 4, 5 and 6).

Y. MASUDA [23] suggested that there exists a vortical ring with positive or negative vorticity, which moves as wave-motion, in a vorticity field, chiefly, from his analysis on vorticity for typhoon "Jane" and made theoretical studies on the ring. $\mathrm{H}$. ARAKAwA and $\mathrm{K}$. Suda [24] made analyses on wind, windwave and swell for the historical typhoon on September 26, 1935, with numbers of observational data by the Japanese Navy that was in manoeuvres in the eastern coast of Japan at the time, and presented the characteristics of these fields in that case.

As for statistical study, one in which the relation between the wind velocities at the various spots and the distances of the spots from the center was investigated, was made by $K$. TAKAHASHI and R. ITo[25]. They pointed out that the following relations between $v$ and $r$ hold; $v \propto r$ in the inner region $(0 \sim 40 \mathrm{~km}), v \propto r^{-1 / 2}$ in the outer region $(40 \sim 500 \mathrm{~km})$, and $v \propto \gamma^{-1}$ at the outside of the typhoon, where $v$ and $r$ represent the wind velocity and the distance from the center respectively. $K$. WATANABE [26] made a statistical study on the eye and pressure of center of tropical cyclones in the Western Pacific during 1949 1950 with observational data by aerial reconnaissance, and also investigated the relation. between the life stage and pressure profile of the typhoon.

Besides, a study on the relation between the source of atmospherics and the position of typhoon was made by S. Kitagawa, T. Iizuka, K. Murai and. M. Kobayashi [27].

\section{Studies on damages caused by typhoons}

Researches and statistics on damages caused by typhoons are summarised in 
the "ljôkisyô hôkoku" (in Japanese), the Geophysical Review (in Japanese) and the Memoirs of the Central Meteorological Observatory (in Japanese), published by C.M.O. for severe typhoons crossing Japan. K. TAKAhAshi[28] presented a synthetic paper on the typhoons. and concluded that heavy rains in Japan are mainly caused by typhoons, either directly or indirectly.

In Table 1, some extreme values of precipitation in Japan are shown, most of which were caused by heavy rains due to direct or indirect effect of typhoons.

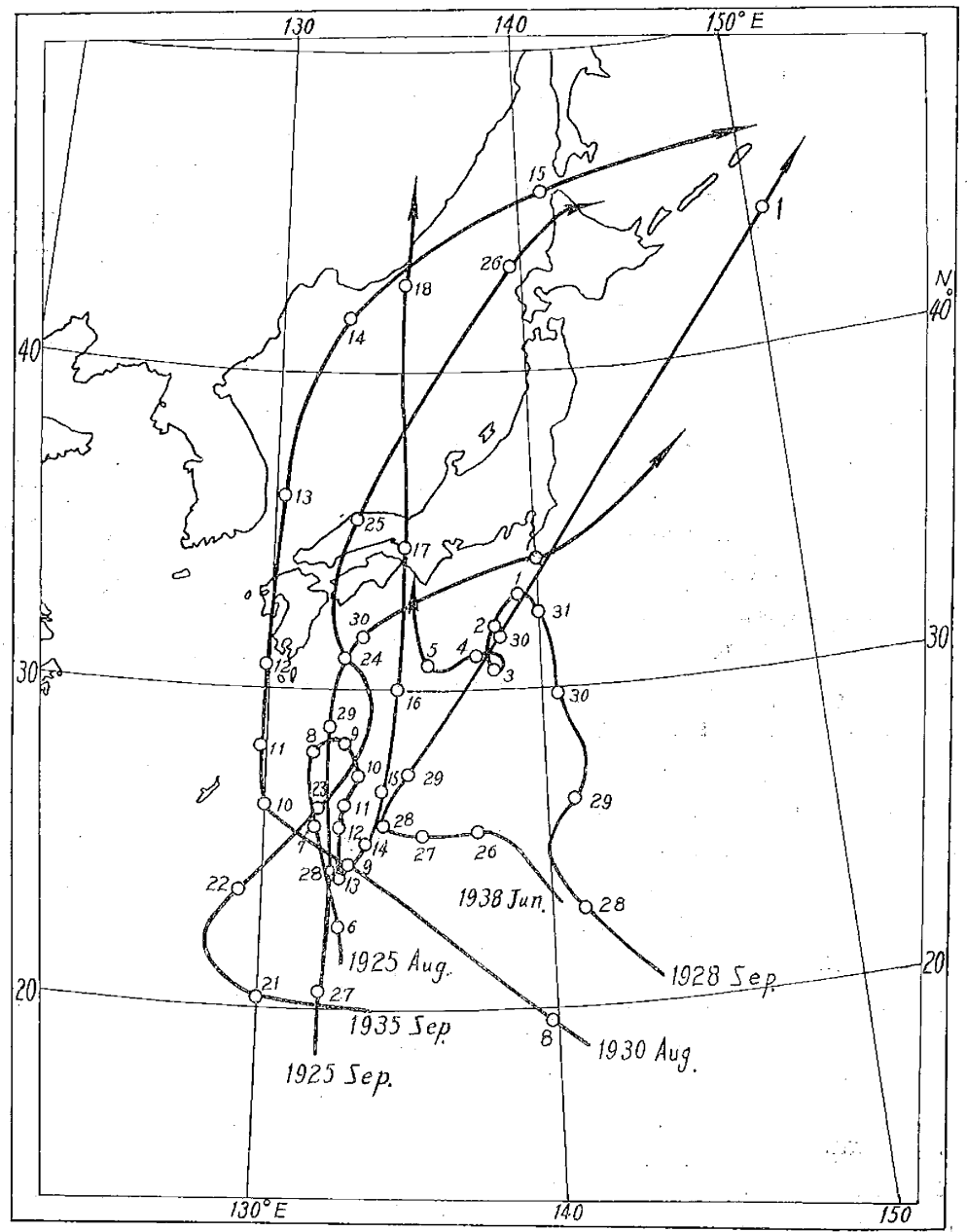

Fig. 7. Paths of typhoons accompanied by extraodinarily heavy rains.

Fig. 7 shows paths of typhoons which bring extraordinarily heavy precipitation in Japan. As seen from this figure, rather abnormal paths seem to bring abnormal heavy rains.

Y. ARAI [29] studied the relation between damages of crops and amounts of precipitation, and presented experimental formulas between them. 
Table 1. Heavy Precipitation in Japan.

\begin{tabular}{l|r|c}
\hline \multicolumn{1}{c|}{ Station } & Date & Precipitation \\
\hline Hikone (Honshu) & 7 th Sept. 1896. & $597 \mathrm{~mm} /$ day \\
Miyazaki (Kyushu) & 24 th Sept. 1886 & 490 \\
Tokushima (Shikoku) & 2 nd Oct. 1912 & 463 \\
Chichibu (Honshu) & 3i st July 1928 & 422 \\
Izuhara (Tsushima Is.) & 24 th Sept. 1930 \\
Nagasaki (Kyushu) & 28 th June 1928 & 393 \\
Shimizu (Shikoku) & 24 th Oct. 1934 & 386 \\
\hline
\end{tabular}

\section{Researches on the movement of typhoon}

H. WADA [30] presented a method of extended forecasting of typhoon movement and derived the relation between the recurvature, retardation and decay of the typhoon and the height of isentropic surface, making an isentropic analysis on typhoons. K. OKuBo and N. Nakamura[31] concluded that the typhoon moves toward the center of the minimum temperature area of stratosphere from their investigations on the relation between the distribution map of minimum temperature in stratosphere and the typhoon track. E. Suzuri[32] computed the correlation coefficient between the moving velocity calculated through kinematical treatment and one measured actually, and also made systematic investigations on the correlation between the track and the upper current, and on the others. H. Matsukura [33] said that a typhoon is apt to move toward the negative area in 15 days mean pressure anomaly chart, investigating the relation between the tracks and the mean pressure distributions. M. HAsнimoto[34] claimed that a typhoon moves along the intermediate direction between one on the general pressure field at the earth's surface and one at $500 \mathrm{mb}$ surface, applying Syono's theory, from which the basic pressure field acting on the typhoon is obtained on the weathermaps at the earth's and $500 \mathrm{mb}$ surface. T. Kamiko's [35] method to predict the path, which applies the vertical instability, is uncommon. He deduced a method to compute the vertical instability, and said that a typhoon moves toward the region where the vertical instability is extreme, from the distribution of the instabilities in typhoons. As for the meandering motion of the typhoon, S. Syono, T. WAtanabe and M. IIda [36] made analyses on it. They made studies on comparison of values of amplitude and period computed through the analyses on the tracks of typhoons during 1950 1951 with those calculated theoretically.

$K$. TAKAhashi [37] gave the formula of typhoon movement under the consideration of the acceleration of the typhoon. Applying it to typhoons of 1952, he obtained fairly satisfactory results.

Researches on relations between the fields of convergence and those of divergence or between the fields of vorticity and the typhoon tracks, are presented by $\mathrm{S}$. Kubota, M. Okuta, T. Asakura and M. IIda [38] and K. Tamura [39]. They showed that the typhoon moves towards the region where vorticity concentrates. T. OCHI [40] claimed that typhoons move along the westerly jet stream in middle latitudes.

As for the statistical study, a series by $K$. TAKAHAsH and his collaborators [41] is recommendable. Namely, K. TAKAHAsH investigated the frequency and 
persistency of the velocity of a typhoon, and the relation between the moving velocity and latitude, and T. ANDo found that the deeper the pressure of the center the larger the moving velocity on the north of $30^{\circ}$ and it is generally the reverse on the south of it, investigating the relation between the moving velocity and the intensity of the typhoon represented by the pressure difference between the center and the extreme closed isobar or by the mean radius of the extreme isobar. $\mathrm{K}$. TAKAhAshi and U. OKuTA showed that the geostrophic wind velocity at $700 \mathrm{mb}$ stands well for the moving velocity and that the $500 \mathrm{mb}$ level is reasonable as the steering level. K. TAkAhashi, M. IIDA and S. Kubota said that a typhoon moves along the isotherms at $700 \mathrm{mb}$ and the more dense the isotherms, the larger its velocity, and also it looks like having a tendency to move toward a low area of thickness pattern. N. NAKAmura said that the trajectory is related to the track of the typhoon through his drawings of trajectory for typhoons for 60 hours before their crossing $20^{\circ} \mathrm{N}$ line, and $\mathrm{T}$. ANDo and M. IIDA said that a typhoon moves along the edge of the North Pacific anticyclones on the prognostic chart drawn under the assumption of a 25-day period for meteorological elements.

Y. Masuda, M. Takeuchi and M. Hashimoto [42] found that there appears a point which corresponds to Scharhag's "Delta-point" in the front of a typhoon and that the point is closer to its center in higher altitudes, making streamline analyses on typhoons. They then claimed that the line connecting these points with the center of typhoon gives the directions of steering current, and that a typhoon moves in this direction.

From the point of view of the so-called "Numerical Weather Prediction.", Y. SASAKI and K. Mryaroda [43] [44] studied on the movement of the typhoon, deriving the instantaneous velocity formula of the typhoon from the barotropic equation. They [45] also proposed a practical forecasting method of typhoon track for more than 12 -hr period, where the change of the general pressure field was taken into account and the stepwise forecasting of the typhoon displacements with respect to time was formulated.

Besides, N. Arizumi[46] and Y. Masuda [3] studied on the vertical velocity distribution, and both concluded that the typhoon moves toward the centre of updraft region.

\section{Theoretical studies}

1) Studies on the structure of the typhoon

S. Syono [47] treated the formation of an area of negative vorticity around a tropical cyclone, on the basis of the vorticity theorem, i.e., ZS=Const, and discussed its necessity in order to converge the integrals of kinetic energy and pressure. Then, he made sure of its existence by the data of Okinawa Typhoon, and emphasized the importance of this region in the structure of the typhoon.

D. Nishimura [48] resolved the three dimensional perturbation equations on the assumption of axial symmetry and the vertical velocity as $w=w_{0} \sin 2 m z$.

A. KASAHARA [49] investigated the structure of the typhoon in the incipient stage and the formation and development of the region of negative vorticity around the positive vorticity area near the typhoon center, solving the three dimensional perturbation euqation, and presented a model for the tropical cyclone in incipient stage, i.e., one consisting of warm centers and rings where updrafts exist and of cold rings where downdrafts do. 
S. Syono $[50,51]$ also studied on the rain which occurs due to the convergence that is represented by the term of vertical component of relative vorticity in gradient wind and caused by friction in the case of circular isobar, as an application of the approximate solution of a non-linear equation. He called it "vortical rain ", and confirmed the existence of such rain by the example of Okinawa Typhoon.

Regarding the theory on formation of the typhoon eye, the following are to be noted. M. MaGata [52] solved the equations of motion on the assumption of stationary, non-friction and axial symmetry and studied on the mechanism of the typhoon eye applying the theorem of conservation of absolute angular momentum. $D$. Nishimura [48] derived a formula for the inclination of wind in the case of circular isobar from the solutions of the two dimensional equations of motion under the condition of axial symmetry, and computed the radius of the eye under the condition that the wind blows only in the tangential direction at the boundary of the eye. T. Watanabe[53] studied the motion of the air mass on the basis of the pressure integration and the theorem of conservation of absolute angular momentum and tried to make expositions upon the formation and maintenance of the multiple eye.

H. Arakawa [54] claimed that the violent turbulence at the center of a typhoon is caused by the existence of the very large positive wind shear over there, applying the criterion of stability obtained through the comparison of the works done by centrifugal force and by Reynolds stress. T. WATANABE[55] presented the discrepancy between the centers of pressure and of wind, through the kinematics of streamline. Besides, N. Nakamura [56] tried to clarify the mechanism of convergence, through the investigation of the paths of air particles by the use of the solutions of the two dimensional equations of motion on the assumption of axial symmetry. As for the estimation of energy of a typhoon, the series of studies by K. Takahashi[57] and T. Ando [58] is to be recommended.

2) Studies on the formation and decay.

S. Syono [59] presented a physical picture of typhoon formation in which the trigger action of typhoon formation is the pressure fall caused by the results of precipitation and then the more essential cause is the convergence in the lower layers rather than the divergence in upper layers. He presented the polytropic change method by which latent instability can be treated dynamically. He concluded the following criterion for the development of perturbation of the typhoon from the three-dimensional perturbation equations:

$$
-g S / \zeta^{2} \gtrless 76 n^{2} r^{2} \quad \begin{array}{ll}
\text { for development } \\
\text { for neutral }
\end{array}
$$

where $g$ : acceleration of gravity, $S$ : vertical thermal stability, $\zeta$ : absolute vorticity, $n$ : number of loops of perturbations on vertical direction, $r$ : size of horizontal perturbation in $100 \mathrm{~km}$ unit.

The left side, which is in the same form as Richardson-number, is named $\mathrm{S}$ number. A discussion was made on the mode of perturbation, and it was concluded that the perturbation which is too broad in horizontal direction or too shallow in vertical direction would not develop. A. KasahaRa [60] studied on the mechanism of filling-up of the typhoon by the use of tendency equation, calculating the mass divergence and isallobaric convergence from the solutions of the two-dimensional equations of motion on the assumption of the axial symmetry. 
3) Studies on the movement of the typhoon.

M. MAgata [61] made an exposition for the "law of steering" assuming a theorem of conservation of absolute angular momentum, and also investigated the motion of a vortex in the general current which has vertical shear.

S. Syono[62] derived equations of motion for the atmospheric vortices in nonuniform pressure field from the integration over the region occupied by the vortices, and came to the following conclusions: (1) Vortices describe a cycloidal path, being affected by RossBy and Coriolis' forces, and the cyclonic vortices move eastward and the anticyclonic westward. (2) Vortices in uniform barometric gradient field show a motion which consists of the following four terms: i) Motion due to geostrophic wind, ii) Cycloidal motion, iii) Motion accelerated zonally, iv) Oscillating motion. (3) A cyclone is apt to move towards isallobaric low. He also made a comparison of his result with C-G. Rossby's results [63] on the motion of atmospheric vortices, and clarified the difference. Furthermore, he [64] derived equations of motion for atmospheric vortices in uniform pressure field and for the cold dome, from the theorems of conservation of kinetic energy and of conservation of absolute angular momentum. K. GAMBo and A. KAsahara [65, 66] derived equations of motion for the rotating solid cylinder on the rotating earth and also investigated the motion of atmospheric vortices, deriving equations of motion for general atmospheric vortices other than rotating solid cylinder. $\mathrm{H}$. ARAKAWA [67] mentioned the similarities of meandering motion of the typhoon to the movement of whirlwind in his study in which the motion of the whirlwind is treated as a motion of a body having circulation around it in uniform flow, i.e., as phugoid motion. M. Yoshitake[68] investigated the motion of the typhoon, deriving equations of motion for the case where the atmospheric vortices are considered to be an open system. He also confirmed that Coriolis' forces and pressure which are almost in balance to each other are the main factors in making an estimation of intensities of various forces acting on a typhoon for a few examples. M. TAKeuchr[69] investigated the motion of atmospheric vortices in the fields of circular, hyperbolic, and linear flows with uniform vorticities, compared his result with the results by S. Syovo[62] and T.C. YEH[70] and with some examples in the western Pacific, and also concluded that the loop path is caused by the oscillating motion and that the moving velocity becomes faster by the oscillating motion.

Y. SASAKI and K. MiYaroda [45] derived the velocity formula of the typhoon for the case where the pressure fields of all levels from top to bottom of the atmosphere are considered to be effective: the velocity thus obtained is of the form such as the weighted mean of the steering winds on every level, where the weighting coefficients are closely connected with some quantities relating to the threedimensional structure of the typhoon. From the consideration of the coefficients, they claimed that on the level where the typhoon is constricted in its vertical cross section the weighting coefficient has a maximum value, and that this level corresponds to the so-called steering level of the typhoon.

Acknowledgement__ The author wishes to express his warmest thanks to Dr. H. Arakawa, Messrs. Y. MASUda and M. TAKEUChI for their assistance in preparing this paper. 


\section{References}

[1] Yamada, H. and Matsuhasir, S., 1950: The Structure of Typhoons. Yohokenkyu-Note (in Japanese). 1, No. 9, p. 40.

[2] Simpson, R. H., 1948: A Note on the Movement and Structure of the Florida Hurricane of October 1946. Month. Weath. Rev., 75, p. 53.

[3] Masuda, Y., 1950: On the Method of Computing Vertical Motion in the Atmosphere, (I, II, III). Papers in Meteoroly and Geophysics. 1, p. 1.

[4] Arakawa, H., 1950: Aerological Observations Made in the "Kitty" Typhoon by the Central Meteorological Observatory, Tokyo. Pap. Met. Geophys. 1, p. 217. , 1950: Vertical Structure of a Mature Typhoon. Month. Weath. Rev., 31, p. 197. 1951: Analysis of the Tropopause and the Stratospheric Field of Temperature of a Mature Typhoon. Pap. Met. Geophys. 2, p. 1.

[5] Hashisoto, M. and Samper, J., 1951: On the Analysis of the Typhoon Kitty. Jour. Met. Soc. Japan, II, 29, p. 255.

[6] Masuta, Y. and TAKEUCh, M., 1951: An Aerological Investigation' of the Structure of the Typhoon. (Analysis of the Typhoons "Jane" and "Kezia"). Pap. Met. Geo. phys., 2, p. 234.

[7] Ka'To, H., 1952: Verícal Structure of Typhoons. Bulletin of 'Takyo District Meteorological Observatory, No. 11, p. 125.

[8] Kobayashi, S., 1951: On the Aerological Condition in "Jane" Typhoon. Memoirs of the Central Meteorological Observatory, 36, p. 190.

[9] UWAI, K., 1951: Analysis of Typhoon "Jane". Memoirs CMO. 36, p. 199.

[10] U WAI, K., 1951: Analysis of the Typhoon "Kezia". Memoirs CMO., 36, p. 437.

[11] UWAI, K., 1950: Analysis of Kathleen Typhoon (II). Analysis of Life History of Typhoon. Journal of Meteorological Research, 2, p. 151.

"._. 1951: On the Typhoons and Tropical Cyclone Groups in 1950 (I). (Generation and Movement of Tropical Storms at the $700 \mathrm{mb}$ Surface.) Journ. Met. Res., 3, p. 418.

..... 1952: Tropopause Wave and Typhoon (I). Geophy. Mag. 23, p. 307.

" , 1953: Tropopause Wave and Typhoon (II). Journ. Met. Res., 5, p. 1.

[12] Kobota, S., 1950: Tropical Low Pressure Area off the South Coast of Japan in August 1950. Memoirs CMO., 35, p. 219.

[13] Arakawa, H., 1952: Mame-Taifu or Midget Typhoon. Geophys. Mag. 23, p. 463.

[14] Kasahara, A., 1953: A Note on the Vertical Structure of the Pressure and Temperature Fields in a Typhoon. Journ. Met. Soc. Japan, II, 31, p. 22.

[15] Arakaiwa, H., 1952: The Characteristic Structure of the Occluded Frontal Typhoon in the Late Fall Other than the Occlusion of Wave Shaped Frontal Perturbations. Journ. Met. Soc. Japan, II, 30, p. 211.

[16] FuJI'A, T. 1949: On the Characteristic Features of the Eye and Upper Currents of the Typhoon "Della". Seibukanku-Kisho-Kenkyukaishi (in Japanese), 7.

" , 1950: On the Mean Weather Maps before and after Passage of the Typhoon "Della". Seibukanku-Kisho-Kenkyukaishi (in Japanese), 8.

" , 1952: Studies on Typhoon and Convection. Report of Meteorological Laboratory, Kyushu Institute of Technology, Kyushu Univ., 1 4, p. 1.

[17] Kasaryara, A., 1950: On the Distribution of the Amount of Rainfall and Filling-up of the "Kitty-Typhoon". Geophysical Notes, 3, No. 30.

[18] ANDo, T., 1951: Rainfall Accompanied Typhoon (I). Journ. Met. Soc. Japan, II, 29, p. 20.

[19] Uwar, K., 1950: Analysis of the Typhoon "Kathleen" (1), Mechanism of Heavy Rainfall and Front in Kanto, Chubu and Tohoku Districts. Geophys. Mag. 21 , p. 147.

, 1950: On the Movement of Rainfall-group (I), Journ. Mët. Res., 2, p. 217.

, 1950: On the Movement of Rainfall-group (II); (Movement of Rainfall-groups 
by the Typhoon “Kitty"). Journ. Met. Res. 2, p. 437.

II__, 1952: On the Movement of Rainfall-group (IV), (Analysis of the Rainfall-groups by the Typhoon "Kezia' and "Jane"). Journ. Met. Soc. Japan, II, 30, p. 241.

[20] Satto, S., 1951: On the Structure of the "Jane" Typhoon. Memoirs. CMO., 36, p. 180.

[21] Hashimoto, K., 1951: On the Internal Region of Typhoon at South Kyushu. Memoirs CMO., 35, p. 427.

[22] Syono, S., Ogura, Y., Gambo, K. and Kasahara, A., 1951: On the Negative Vorticity in a Typhoon. ' Journ. Met. Soc. Japan, II, 29, p. 1.

[23] MasUda, Y., 1952: On the Small Perturbations Superposing Upon the Circular Vortex. Pap. Met. Geophys., 3, p. 138.

[24] Arakawa, H. and Suda, K., 1953: Analysis of Winds, Wind Waves and Swell over the Sea to the East of Japan during the Historical Typhoon of September 26, 1935. Month. Weath. Rev. 81, No. 2.

[25] Takahashi, K. and Ito, R., 1950: Distribution of Surface Wind Velocity in Typhoon. Memoirs CMO., 35, p. 239.

[26] Watanabe, K., 1951: Some Studies on Typhoons of 1949 and 1950 (Part I. Typhoon Eye). Journ. Met. Soc. Japan, II, 29, p. 314.

_. , 1952: Some Studies on the Mechanism of Typhoon (Part II. Pressure). Journ. Met. Soc. Japan, II, 30, p. 126.

[27] Kitagawa, S., Iizuka, T., Mukar, K. and Kobayashi, M., 1953: Location of Atmospherics and Their Relation to Meteorological Phenomena. Journ. Met. Soc. Japan, II, 31 , p. 37.

[28] TaKahashi, K., 1948: Typhoon in Japan. Geophys. Mag., 17, p. 1.

[29] Arai, Y., 1954: On Damages Caused by Heavy Rains (in Japanese). Tenki, 1, p. 12.

[30] WADA, H., 1950: On the Forecasting of Typhoon Tracks According to the Isentropic Analysis (in Japanese). Journ. Met. Res., 1, p. 59.

[31] Okumo, K. and Nakamura, N., 1950: On the Cold Area of Stratosphere in the Case of Typhoons. Journ. Met. Soc. Japan, II, 28, p. 107.

[32] Suzuki, E., 1950: Stochastic Researches on the Tracks of Typhoons (I), (II) (in Japanese). Journ. Met. Res., 1, p. 183.

[33] Matsukura, H., 1950: A Study on the Movement of Typhoon. Journ. Met. Res., 2, Supplementary number, p. 51.

[34] Hashimoto, M., 1951: On the Movement of Typhoon (2). Journ. Met. Res., 3, p. 467.

[35] Kamiko, T., 1951: Distribution of Vertical Instability in the Neighbourhood of Tropical Cyclones. Journ. Met. Soc. Japan, II, 29, p. 194.

[36] Syono, S., Watanabe, T. and Irda, M., 1952: On the Meandering Motion of Typhoons (in Japanese). Kagaku, 22, p. 311.

[37] Takahashi, K., 1953: A Method of the Typhoon Movement Forecast Considering the Inertia Term. Journ. Met. Res., 5, p. 587.

[38] Kubota, S., Okuta, M., Asakura, T. and I IDA, M., 1953: Distribution of Vorticity and Path of Typhoon. Journ. Net. Res., 5, p. 597.

[39] Tamura, T., 1954: Relation between the Fields of Convergence and Divergence and Path of Typhoon. (to be published).

[40] Ochi, T., 1954: On Relation between Maximum Wind Velocity Zone and Typhoon Track (to be published).

[41] Takahasiin, K. and Colraborators, 1952: On the Movement of Typhoons. Journ. Mer. Res., 4, p. 1.

[42] Masuda, Y., TAKeuchl, M. and Hashimoto, M., 1953: On the Forecasting of the Movement of Typhoon. Pap. Met. Geophys., 3, p. 246.

[43.] SASAKI, Y. and MiYaKona, K., 1954: Numerical Forecasting of the Movemet of Cyclone. Journ. Met. Soc. Japan, 32.

[44] SaSAKI, Y., 1954: Numerical Forecasting of the Movement of Typhoon (in press). 
[45] Sasaki, Y. and Miyakoda, K., 1954: Numerical Prediction of Tropical Cyclone Tracks (to be published).

[46] Arızum, N., 1950: A Diagramatic Method of Computing Vertical Motion in the Atmosphere and Its Applications. Geophys. Mag., 22, p. 131.

[47] Syono, S., 1951: On the Structure of Atmospheric Vortices. Journ. Meteor., 8, p. 103.

[48] Nishimura, D., 1950: On the Structure of Typhoon. Geophys. Mag., 21, p. 107.

[49] Kasahara, A., 1952: The Structure of a Tropical Cyclone in the Incipient Stage. Geophys. Mag., 24, p. 129.

[50] Syono, S., 1950: On the Vortical Rain. Geophys. Notes, 3. No. 25.

[51] Syono, S., 1944: Approximate Solution of Non-line sr Differential Equation of Stationary Wind in Axial-symmetric Cyclone and Anticyclone, and Its Applications. Journ. Met. Soc. Japan, II, 22, p. 365 or Geoplyys. Mag., 20 (1949), p. 43.

[52] MAGATA, M., 1950: Dynamics of the Eye of Storm. Pap. Met. Geophys., 1, p. 29.

[53] Watanabe, T., 1951: Dynamical Study of the Eye of Typhoon. Journ. Met. Res., 3, p. 151.

" , 1950: Dynamics of the Eye of Typhoon. Memoirs CMO., 35, p. 332.

[54] Arakawa, H., 1952: Severe Turbulence Resulting from Excessive Wind-shear in Tropical. Cyclones. Journ. Meteor., 9, p. 221.

[55] Watanabe, T., 1950: Relation between the Wind Center and the Pressure Center. Memoirs CMO., 35, p. 250.

[56] Naramura, N., 1950: Wind and Converging Air Current in Typhoon. Memoirs CMO., 35 , p. 257.

[57] Takahashi, K., 1950: Estimation of Various Energies of Typhoon. Memoirs CMO., 35, p. 268.

[58] AN1o, T., 1950: Energy Equation. Memoirs CMO., 35, p. 262.

" , 1950: Energies of the "Kitty" and "Kezia" Typhoons. Memoirs CMO., 35, p. 284.

[59] Syono, S., 1953: On the Formation of Tropical Cyclones. Tellus, 5, p. 179.

[60] Kasahara, A., 1949: On the Filling-up of Typhoon. Geophys. Notes, 2, No. 13.

[61] MAGATA, M., 1950: Dynamics of the Movement of Atmospheric Vortices. Pap. Met. Geophys., 1, p. 38.

[62]. Syono, S., 1951: On the Motion of a Vortex in a Non-uniform Pressure Field (Provisional report). Pap. Met. Geophys., 2, p. 117.

[63] Rossisy, C.-G., 1948: On the Displacement and Intensity Changes of Atmospheric Vortices. Journ. Mar. Res., 5, p. 175.

" , 1949: On the Mechanism for the Release of Potential Energy in the Atmosphere. Jour. Met., 6, p. 163.

[64] Syono, S., 1952: Note on the Motion of Atmospheric Vortices. Geophys. Mag., 23, p. 423.

[65] Gambo, K. and Kasahara, A., 1952: Notes on the Motion of a Rotating Solid Cylinder on a Rotating Earth. Journ. Met. Soc. Japan, II, 30, p. 1.

[66] Gammo, K. and Kasamara, A., 1951: The General Treatment of the Motion of Atmospheric Vortices. Geophys. Notes, 4, No. 8.

[67] Araisawa, H., 1952: Phugoid Motion of Whirlwinds in the Atmosphere. Geofysica Pura. e Applicata-Milano, 22, p. 3.

[68] Yoshitake, M., 1953: On the Dynamics of Open Systems and Its Application to the Motion. of Typhoons. Geophys. Mag., 24, p. 193.

[69] Takeuchi, M., 1953: The Motion of Tropical Cyclones in a Non-uniform. Flow Field. Pap. Met. Geophys., 3, p. 252.

[70] Y.er, T.C., 1950: The Motion of Tropical Storms under the Influence of a Superimposed. Southerly Current. Journ. Met. 7, p. 108. 